\title{
Forecasting Reference Evapotranspiration Using Time Lagged Recurrent Neural Network
}

\author{
GEORGIOS PROIAS ${ }^{1}$, IOANNIS GRAVALOS ${ }^{2}$, ELPINIKI PAPAGEORGIOU ${ }^{3}$, \\ KATARZYNA POCZĘTA ${ }^{4}$, MARIA SAKELLARIOU-MAKRANTONAKI ${ }^{1}$ \\ ${ }^{1}$ Department of Agriculture Crop Production and Rural Environment, School of Agricultural Sciences, \\ University of Thessaly, 38446 Volos, GREECE \\ ${ }^{2}$ Department of Agrotechnology, School of Agricultural Sciences, \\ University of Thessaly, 41500 Larissa, GREECE \\ ${ }^{3}$ Department of Digital Systems, School of Technology, \\ University of Thessaly, 41500 Larissa, GREECE \\ ${ }^{4}$ Kielce University of Technology, al. Tysiąclecia Państwa Polskiego 7, 25-314 Kielce, POLAND
}

Abstract: - The aim of this study is to employ a Time Lagged Recurrent Neural Network (TLRNN) model for forecasting near future reference evapotranspiration $\left(\mathrm{ET}_{\mathrm{o}}\right)$ values by using climate data taken from meteorological station located in Velestino, a village near the city of Volos, in Thessaly, centre of Greece. TLRNN is Multilayer Perceptron Neural Network (MLP-NN) with locally recurrent connections and short-term memory structures that can learn temporal variations from the dataset. The network topology is using input layer, hidden layer and a single output with the $\mathrm{ET}_{\mathrm{o}}$ values. The network model was trained using the back propagation through time algorithm. Performance evaluations of the network model done by comparing the Mean Bias Error (MBE), Root Mean Square Error (RMSE), Coefficient of Determination $\left(\mathrm{R}^{2}\right)$ and Index of Agreement (IA). The evaluation of the results showed that the developed TLRNN model works properly and the forecasting $\mathrm{ET}_{\mathrm{o}}$ values approximate the FAO-56 PM values. A good proximity of predictions with the experimental data was noticed, achieving coefficients of determination $\left(\mathrm{R}^{2}\right)$ greater than $75 \%$ and root mean square error (RMSE) values less than $1.0 \mathrm{~mm} /$ day. The forecasts range up to three days ahead and can be helpful to farmers for irrigation scheduling.

Key-Words: - Evapotranspiration, Water management, Time series forecasting, Neural network model

Received: May 14, 2020. Revised: September 17, 2020. Accepted: October 20, 2020.

Published: October 23, 2020.

\section{Introduction}

Irrigation scheduling is one of the most important procedures in irrigation science and technology as it plays a crucial role in water resource management. The water resource management strategies should be balanced between water supply and demand within a time-frame of quantitative and qualitative conservation of the characteristics of these resources [1].

The irrigation water needs of a crop are defined as those that produce the maximum economic impact. These needs are expressed by the crop evapotranspiration $\left(\mathrm{ET}_{\mathrm{c}}\right)$. Crop evapotranspiration is based on the calculation of the reference evapotranspiration $\left(\mathrm{ET}_{\mathrm{o}}\right)$ and on the plant coefficients $\left(\mathrm{K}_{\mathrm{c}}\right)$ that represent the growth differences of the crops. The FAO PenmanMonteith (FAO-56 PM) equation has been recommended as the standard method for calculation of the $\mathrm{ET}_{\mathrm{o}}$ [2-4].

Forecasting should be an integral part of the decision-making activities of farm management, as it can play an important role in many areas. Modern farms require short-term, medium-term and longterm forecasts, depending on the specific application. The forecasting methods depend largely on available data. A forecasting task usually involves the following steps: a) problem definition, b) gathering information, c) preliminary analysis, d) choosing and fitting models, e) using and evaluating a forecasting model [5].

In irrigation management, the terms "forecast" and "forecasting" are reserved for estimates the water status of plants at future times as accurately as possible, based on historical data and knowledge of any future events that might impact the forecasts [6]. Climate-based data are used to perform $\mathrm{ET}_{\mathrm{o}}$ 
forecasting. Although the availability of climate data may be satisfactory, nevertheless there are still challenges with $\mathrm{ET}_{\mathrm{o}}$ forecast, as good accuracy is required depending on the good quality of the weather data retrieved from public sources. The procedures for $\mathrm{ET}_{\mathrm{o}}$ forecast were derived from simple models, commonly from empirical equations based on temperature. However, the $\mathrm{ET}_{\mathrm{o}}$ is a nonlinear physical complex process, which makes the empirical equations to often fail in computing the relationship between weather, soil and crops factors [7]. In recent years, soft computing methods have been studied and used for modeling the $\mathrm{ET}_{\mathrm{o}}$ as a function of climatic data. Soft computing methods include Fuzzy Logic (FL), Genetic Algorithms (GAs), and Artificial Neural Networks (ANNs) [812].

ANNs have more applications in irrigation and $\mathrm{ET}_{\mathrm{o}}$ calculations when compared with other soft computing methods [13]. For instance, Chauhan and Shrivastava [14] studied the ability of AANs to estimate the $\mathrm{ET}_{\mathrm{o}}$ in comparison to climatic based methods. The analysis of results showed that ANN model estimated $\mathrm{ET}_{\mathrm{o}}$ with high reliability. Traore et al. [15] investigated a multilayer feed forward backpropagation neural network (BPNN) for estimation of $\mathrm{ET}_{\mathrm{o}}$ nonlinear complex process using limited climatic data. The results showed that BPNN temperature-based model has better performance in comparison to the empirical Hargreaves method. In addition, it was found that relative humidity and wind velocity improved the BPNN accuracy when applied into the models inputs. Tabari and Hosseinzadeh Talaee [16] examined four multilayer perceptron (MLP) networks comprising various combinations of meteorological data for estimating $\mathrm{ET}_{\mathrm{o}}$. The MLP network that uses all of meteorological data showed best estimation for $\mathrm{ET}_{\mathrm{o}}$ in comparison to the other MLP networks. Traore et al. [17] developed four ANNs learning algorithms (Generalized Feedforward (GFF), Linear Regression (LR), Multilayer Perceptron (MLP) and Probabilistic Neural Network (PNN)) for forecasting $\mathrm{ET}_{\mathrm{o}}$ values by using restricted climate information retrieved from public weather forecast source. The results showed that minimum $\left(\mathrm{T}_{\min }\right)$, maximum $\left(\mathrm{T}_{\max }\right)$ daily air temperatures and net solar radiation $\left(R_{s}\right)$ input dataset yielded the highest performances with the Multilayer Perceptron (MLP) backpropagation network capable to reproduce the closest values to the observed FAO-56 PM method. Short periods of field data from low-cost sensors were used by Kelley and Pardyjak [18], to first train the ANN to estimate actual evapotranspiration
$\left(\mathrm{ET}_{\mathrm{a}}\right)$. This approach demonstrated that can estimate site-specific and crop specific ET.

In this study used a Time Lagged Recurrent Neural Network (TLRNN), which is Multilayer Perceptron Neural Network (MLPNN) with locally recurrent connections and short-term memory structures that can learn temporal variations from the dataset [19]. TLRNN provides a way to approximate any nonlinear function as $\mathrm{y}=\mathrm{f}(\mathrm{x}, \mathrm{w})$, where $\mathrm{w}$ is a set of weight parameters [20]. It is useful for time-series prediction applications, system identification, etc. A TLRNN is found to be suitable for forecasting suspended sediment load occurring episodically during the storm events in river basins [21]. Kote and Jothiprakash [22] used TLRNN for river level prediction. Saharia and Bhattacharjya [23] developed a model using TLRNN to estimate runoff for river Dikrong, a tributary of river Brahmaputra in India. It should be noted that there is a very limited literature related to TLRNNs application in forecasting of $\mathrm{ET}_{\mathrm{o}}$. The aim of this research is to forecast near future reference evapotranspiration $\left(\mathrm{ET}_{\mathrm{o}}\right)$ values by means of a TLRNN model.

\section{Materials and Methods}

The methodology followed in this research is illustrated in Fig.1. First step is the data collection. The next step involves data processing. Then TLRNN model was developed, validated, and tested.

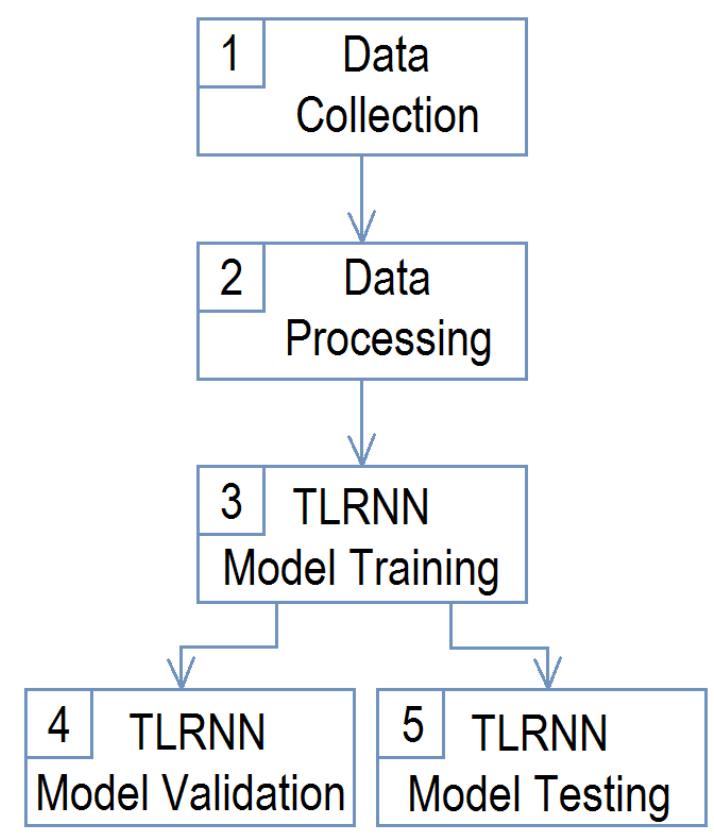

Fig.1. Methodology flowchart. 
The above methodology can be used to estimate $\mathrm{ET}_{\mathrm{o}}$. Moreover, given enough information, correlation is adequate to make robust and informative predictions of $\mathrm{ET}_{\mathrm{o}}$. However, it has limitations. It can be influenced by the quantity and quality of input data.

\subsection{Study area}

Meteorological data were available from the meteorological station located in Velestino, village in Magnesia regional unit that is situated at the south-eastern end of the Thessalian Plain, $17 \mathrm{~km}$ west of Volos and $40 \mathrm{~km}$ southeast of Larissa, central Greece (Fig.2).

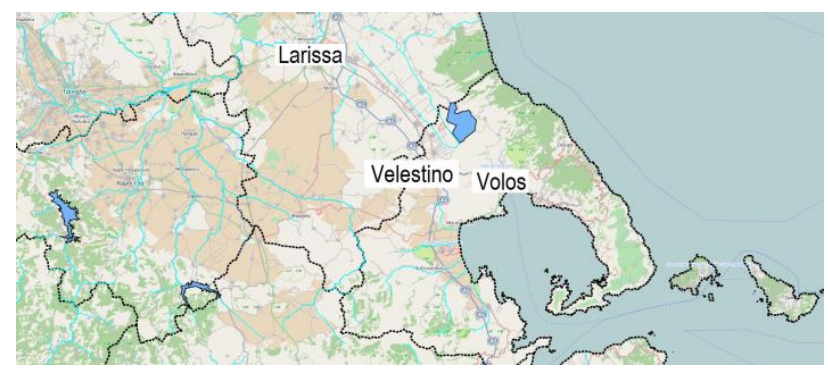

Fig.2. Location map of the study area (Source: GEODATA.gov.gr).

\subsection{Empirical ET model}

Wind speed, air temperature, relative humidity data as well as radiation values were used for the initial calculation of $\mathrm{ET}_{\mathrm{o}}$ as defined by the FAO-56 PM method [24]. This is calculated according to equation (1).

$E T_{O}=\frac{0.408 \cdot \Delta \cdot\left(R_{n}-G\right)+\gamma \cdot \frac{900}{T+273} \cdot u_{2} \cdot\left(e_{s}-e_{a}\right)}{\Delta+\gamma \cdot\left(1+0.34 \cdot u_{2}\right)}$

where $\mathrm{ET}_{0}$ reference evapotranspiration $\left(\mathrm{mm} \mathrm{day}^{-1}\right)$, $R_{n}$ net radiation at the crop surface $\left(\mathrm{MJ} \mathrm{m}^{-2}\right.$ day $\left.^{-1}\right), G$ soil heat flux density ( $\mathrm{MJ} \mathrm{m}^{-2}$ day $\left.^{-1}\right), \mathrm{T}$ daily air temperature at $2 \mathrm{~m}\left({ }^{\circ} \mathrm{C}\right), \mathrm{u}_{2}$ wind speed at $2 \mathrm{~m}(\mathrm{~m}$ $\left.\mathrm{s}^{-1}\right)$, $e_{\mathrm{s}}$ saturation vapour pressure $(\mathrm{kPa}), \mathrm{e}_{\mathrm{a}}$ actual vapour pressure $(\mathrm{kPa}), \mathrm{e}_{\mathrm{s}}-\mathrm{e}_{\mathrm{a}}$ saturation vapour pressure deficit $(\mathrm{kPa}), \Delta$ slope vapour pressure curve $\left(\mathrm{kPa}{ }^{\circ} \mathrm{C}^{-1}\right)$, and $\gamma$ psychrometric constant $(\mathrm{kPa}$ $\left.{ }^{\circ} \mathrm{C}^{-1}\right)$.

\subsection{TLRN model}

There are various designs of ANNs aimed to performed on different tasks. The designs used in making neural network predictions can be classified from the simplest that are easy to implement, through the more complex and more powerful. In this study, we focused exclusively on the Time-
Lagged Recurrent Neural Network (TLRNN). Neural network model was developed using Neurosolutions package. Fig. 3 gives an illustration of the TLRNN architecture. This architecture was adopted to model the relationship between input and output values. It represents a framework to investigate the ability of neural network to forecast $\mathrm{ET}_{0}$, due to the flexibility of using different processing elements, containing feedback and delay line taps to express dynamic behaviour. TLRNN has short-term memory structures to store the data input, one hidden layer with nonlinear processing elements connected directly to the current input taps and the feedback loops of the output memory structures. A standard threshold processing element is also included to adjust the output. One hidden layer is sufficient for the majority of problems. It should be noted that the number of neurons in the hidden layer is a parameter which influences the network performance. If a large number of neurons are used in the hidden layer, then the network training time is increased. On the other hand, if a small number of neurons applied, it can also lead to an accuracy problem. The number of nodes in the hidden layer was determined by trial and error procedure. Finally, output layer contains another short-term memory structures with delay feedback loops to the hidden layer processing elements. This architecture shows increased flexibility by the design of the processing elements, containing feedback and delay line taps to express dynamic behaviour. TLRNN is an advanced network, the purpose of which is to forecast or classify time-varying problems using recurrency as a way to provide memory of the past time periods.

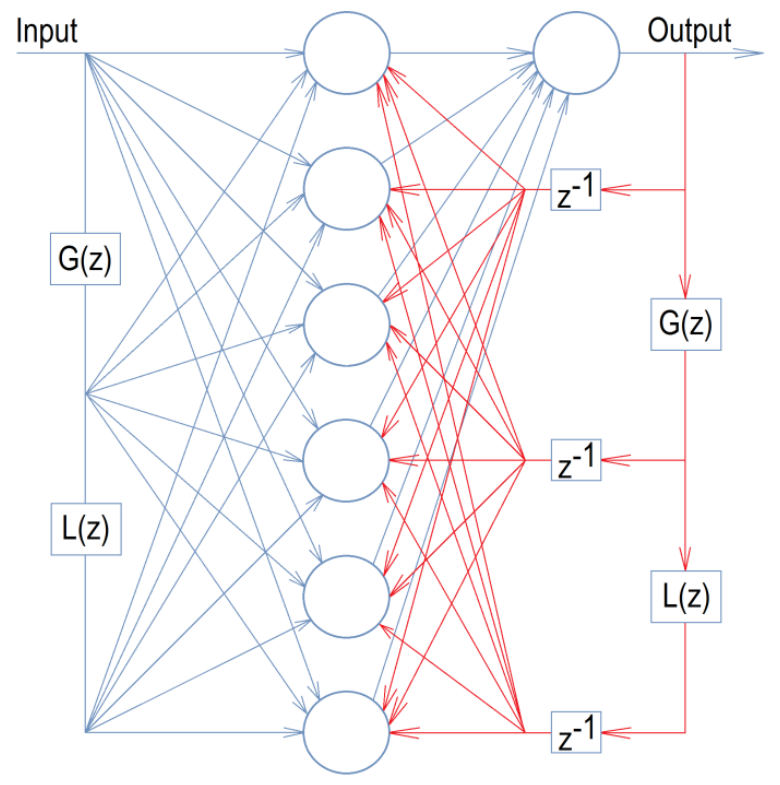

Fig.3. Architecture of the developed TLRNN model. 
There are three main memory structures to choose such as Tapped Delay Line (TDL), Gamma and Laguerre. Memories can be included to any layer in the network, producing very sophisticated neural topologies very useful for time series forecast. In this study, the Gamma and Laguerre memories are selected. They are used in the network to remember past signals. The Gamma memory allows a trade-off between memory resolution (R) and memory depth (D) via the parameter $\mu$. Memory depth refers to how far into the past the memory stores information relative to the memory size and it is given by: $\mathrm{D}=\mathrm{K} / \mu$. This means that the neural network can control the depth of the memory by changing the value of the feedback parameter, instead of changing the number of inputs. Memory resolution refers to the degree to which information concerning the elements of the input sequence is preserved and it is approximated by: $\mathrm{R}=\mu$. The $\mathrm{k}^{\text {th }}$ order of Gamma memory is characterized by the relation: $\mathrm{K}=\mathrm{DxR}$ [25]. The Gamma memory structure is defined by the transfer function $G(z)$ shown below in equation (2).

$$
G(z)=\frac{z^{-1}-(1-\mu)}{1-(1-\mu) z^{-1}}
$$

where $\mu$ is an adaptive parameter (for the short-term memory to be stable $0<\mu<2$ ).

The Laguerre memory is a more general structure as it includes the Gamma memory. The Laguerre memory is composed of a low-pass filter and a cascade of i-1 similar all-pass filter. The tap signals are obtained by the convolution of the lowpass filtered input with an orthogonal set of the allpass functions. Thus, it is less correlated to a Gamma memory and the adaptation speed becomes faster [26]. In the $\mathrm{z}$-domain, the $\mathrm{i}^{\text {th }}$ Laguerre function is computed by equation (3).

$$
L_{i}(z, \mu)=\sqrt{1-(1-\mu)^{2}} \frac{\left(z^{-1}-(1-\mu)\right)^{i-1}}{\left(1-(1-\mu) z^{-1}\right)^{i}}
$$

There are four main ways to train a TLRNN model, all of which based on different methods. In this study, TLRNN uses a learning algorithm that is known as backpropagation through time (BPTT). The general form of BPTT contains the following steps: a) forward calculation, b) calculation of result (error, utility), c) calculation direct derivatives of error with respect to outputs of forwards calculations, d) backpropagate through forwards calculation (calculating running totals where appropriate). The outputs of the TLRNN at each time have two ways of changing the total error: a) direct way when the current predictions are different from the current targets, b) indirect way based on the impact of outputs on errors in later time periods. BPTT can adapt the depth of the memory using different types of learning rules, instead of changing the number of inputs. The best learning rule for each layer for the studied data was backpropagation. Training of the TLRNN was done with BPTT with trajectory learning and the parameters were learned via examples. The network has to be run forward in time until the end of the trajectory and the activation of each processing element must be stored locally in a memory structure for each time step. Then the output error is computed, and the error is backpropagated across the network. An analytical discussion of BPTT is available in Werbos [27], Jothiprakash and Kote [28].

The input-training data procedure was based on a series of parameters such as the month number (in sequence), the day number (in sequence), the total daily rainfall in $\mathrm{mm}$, the maximum and minimum air temperature in ${ }^{\circ} \mathrm{C}$, the maximum and minimum relative air humidity in $\%$, the maximum wind speed during the $24 \mathrm{~h}$ of a day in $\mathrm{m} / \mathrm{sec}$, the total solar radiation on horizontal surface in $\mathrm{W} / \mathrm{m}^{2}$. The data for a period of six years from 2014 to 2018 was used for training the models, whereas the remaining data for a period of two years from 2017 to 2018 was used for validation purpose. $\mathrm{ET}_{\mathrm{o}}$ data was separated into three parts, with $60 \%$ for training, $20 \%$ as cross validation for evaluating the TLRNN model performance and $20 \%$ for testing the model on data not seen before. TLRNN model was designed and tested rigorously for various number of lag, number of neuron at hidden layer and with different values of memory adaptive parameter.

The stopping criteria for the training of the developed TLRNN in the present study is either a maximum of 150 epochs or training is set to terminate when the error sum of squares of the cross validation testing data set begins to increase. The stopping of the training process is used to keep the system from over-fitting the training data.

\subsection{Model performance evaluation}

Four statistical indicators, the coefficient of determination $\left(\mathrm{R}^{2}\right)$, the root mean square error (RMSE), the index of agreement (IA) and the mean bias error (MBE), were also used to evaluate the performance of the TLRNN model [29].

Mean Bias Error (MBE) is used to describe how much the TLRNN model underestimates or overestimates the situation [30]. This is calculated according to equation (4). 


$$
M B E=\frac{1}{n} \cdot\left(\sum_{i=1}^{n}\left(P_{i}-O_{i}\right)\right.
$$

where $\mathrm{n}$ is the number of data points, $\mathrm{P}_{\mathrm{i}}$ the predicted data point, $\mathrm{O}_{\mathrm{i}}$ the observed data point.

Root Mean Square Error (RMSE) is one of the most commonly-used statistics which measures the difference between observed and model-predicted values [31]. A RMSE value closer to zero indicates better model performance. This is calculated according to equation (5).

$$
R M S E=\frac{1}{n} \cdot\left(\sum_{i=1}^{n}\left(P_{i}-O_{i}\right)^{2}\right)^{\frac{1}{2}}
$$

where $\mathrm{n}$ is the number of data points, $\mathrm{P}_{\mathrm{i}}$ the predicted data point, $\mathrm{O}_{\mathrm{i}}$ the observed data point.

Coefficient of Determination $\left(\mathrm{R}^{2}\right)$ is used to explain how much of the observed variability is accounted by the predicted model [30]. $\mathrm{R}^{2}$ will have a value between 0 and $1\left(0 \leq R^{2} \leq 1\right)$. A value of $R^{2}$ near 0 indicates that the model explains none of the variability of the response data around its mean, whereas a value of $\mathrm{R}^{2}$ near 1 indicates that the model explains all the variability of the response data around its mean. $\mathrm{R}^{2}$ is calculated according to equation (6).

$$
R^{2}=\frac{\sum_{i=1}^{n}\left(P_{i}-O_{i \text { ave }}\right)^{2}}{\sum_{i=1}^{n}\left(O_{i}-O_{\text {i ave }}\right)^{2}}
$$

where $\mathrm{n}$ is the number of data points, $\mathrm{P}_{\mathrm{i}}$ the predicted data point, $\mathrm{O}_{\mathrm{i}}$ the observed data point, $\mathrm{O}_{\text {iave }}$ is the average of observed data.

Index of Agreement (IA) is used as a standardized measure of the degree of model prediction error which varies between 0 and 1 [32]. The agreement value of 1 indicates a perfect match, and 0 indicates no agreement at all. IA calculated according to equation (7).

$$
I A=1-\frac{\sum_{i=1}^{n}\left(P_{i}-O_{i}\right)^{2}}{\sum_{i=1}^{n}\left(\left|P_{i}-O_{\text {i ave }}\right|+\left|O_{i}-O_{\text {i ave }}\right|\right)^{2}}
$$

where $\mathrm{n}$ is the number of data points, $\mathrm{P}_{\mathrm{i}}$ the predicted data point, $\mathrm{O}_{\mathrm{i}}$ the observed data point, $\mathrm{O}_{\text {iave }}$ is the average of observed data.

\section{Results and Discussions}

Fig.4, Fig.5 and Fig.6 show the comparison between estimated $\mathrm{ET}_{0}$ values (blue line) by the FAO-56 PM method and the forecasted $\mathrm{ET}_{\mathrm{o}}$ values (red line) by the developed TLRNN model for one, two and three days ahead, respectively. The TLRNN forecasted $\mathrm{ET}_{\mathrm{o}}$ values agreed with the FAO-56 PM estimated $\mathrm{ET}_{\mathrm{o}}$ values and followed the same trend. A visual inspection of the FAO-56 PM estimated $\mathrm{ET}_{0}$ and TLRNN forecasted $\mathrm{ET}_{\mathrm{o}}$ clearly demonstrates the potential of TLRNN modelling. The results obtained in the present study partially verify Ferreira and da Cunha [33], and Yin et al. [34] who reported better performances for a Convolutional Neural NetworkLong Short-Term Memory (CNN-LSTM) and a Bidirectional Long Short-Term Memory model (BiLSTM), respectively. For TLRNN higher values were not found to be trained more correctly. It is obvious by the Figs. 4, 5 and 6 . This can be due to the availability of a lower number of training patterns for higher values and lesser number of input parameters to the TLRNN to fully capture the nonlinearity in the interacting climatic factors particularly during the peak values [35].

Fig.7, Fig.8 and Fig.9 show the scatter plots between $\mathrm{ET}_{\mathrm{o}}$ estimated using the FAO-56 PM method and forecasted by TLRNN model for one, two and three days ahead, respectively. Figures shown that in the first day the forecast of the TLRNN model was better fit than the other two days. The $\mathrm{R}^{2}$ value indicates that $80.0 \%$ of the total variation in forecasted $\mathrm{ET}_{\mathrm{o}}$ is explained by the observed $\mathrm{ET}_{\mathrm{o}}$ values. This result is in agreement with Abrahart and See [36], and Le et al. [37], where the authors argued that the neural network models are efficient in capturing complex, dynamic and non-linear relationships of the physical process being modeled.

Table 1 shows the performance evaluation of the TLRNN model with corresponding MBE, RMSE, and IA values. Lower value of RMSE $(0.9 \mathrm{~mm} /$ day $)$ indicates superior model efficiency. The MBE values, shows that the model makes a small overestimation of the $\mathrm{ET}_{\mathrm{o}}$ on an average basis of 0.1 $\mathrm{mm} /$ day. The IA indicator is very close to the unit, indicating that the predicted values of the model for the next three days are close enough to the observed $\mathrm{ET}_{\mathrm{o}}$. Therefore, the developed TLRNN model for the next three days shows a satisfactory prognostic ability. Similarly, Mulualem and Liou [38] applied seven ANN models incorporating hydrometeorological, climate, sea surface temperatures, and topographic data for crop ET estimate in in the Upper Blue Nile basin of Ethiopia. They reported that coefficient of determination and the root-meansquare error of the best architecture ranged from 0.820 to 0.949 and 0.263 to 0.428 , respectively. 


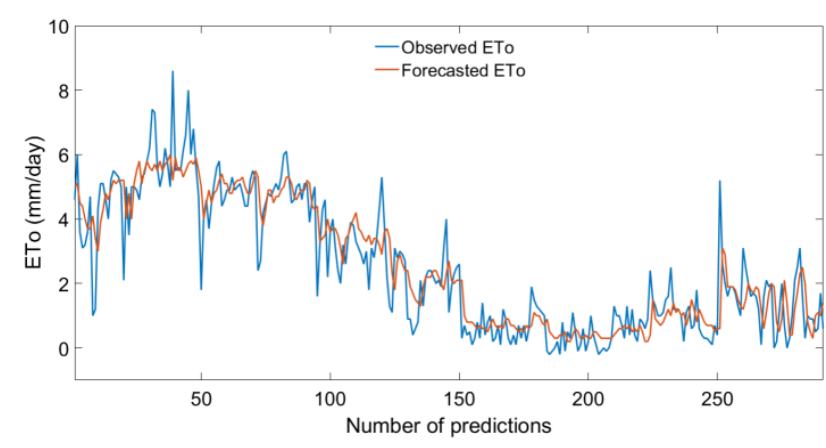

Fig.4. Comparison between observed and forecasted $\mathrm{ET}_{\mathrm{o}}$ for one day ahead.

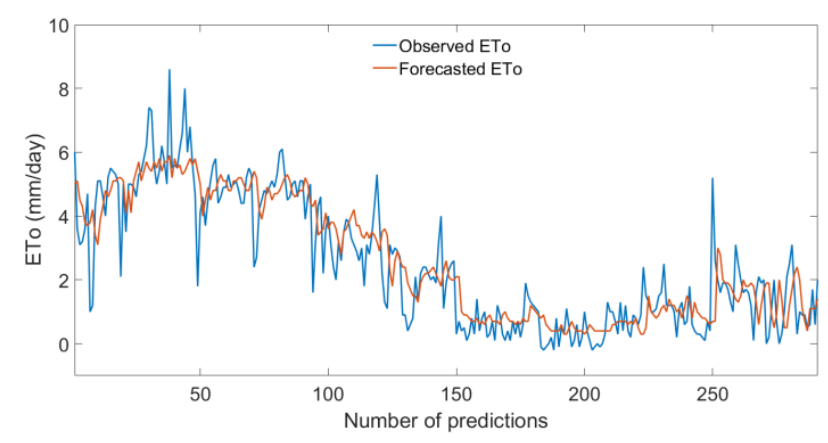

Fig.5. Comparison between observed and forecasted $\mathrm{ET}_{\mathrm{o}}$ for two days ahead.

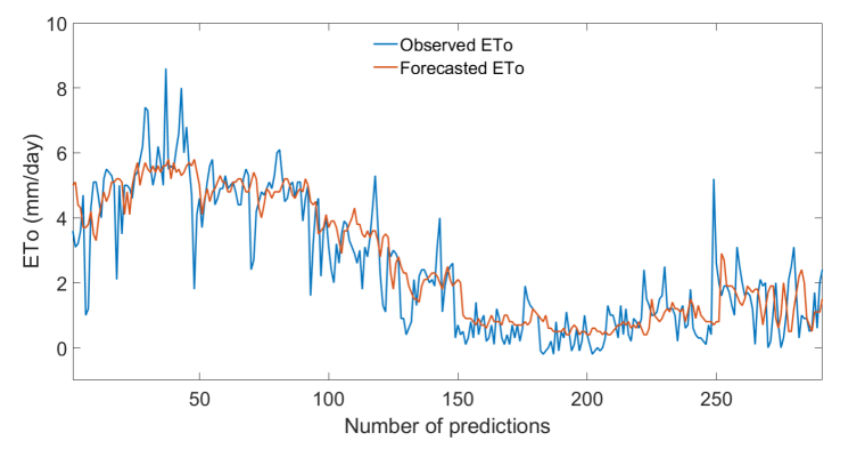

Fig.6. Comparison between observed and forecasted $\mathrm{ET}_{\mathrm{o}}$ for three days ahead.

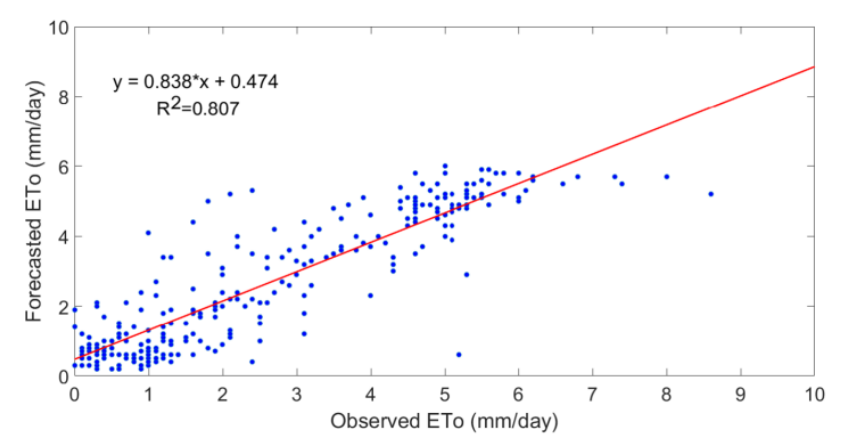

Fig.7. Scatter plot of the observed versus the forecasted $\mathrm{ET}_{\mathrm{o}}$ for one day ahead.

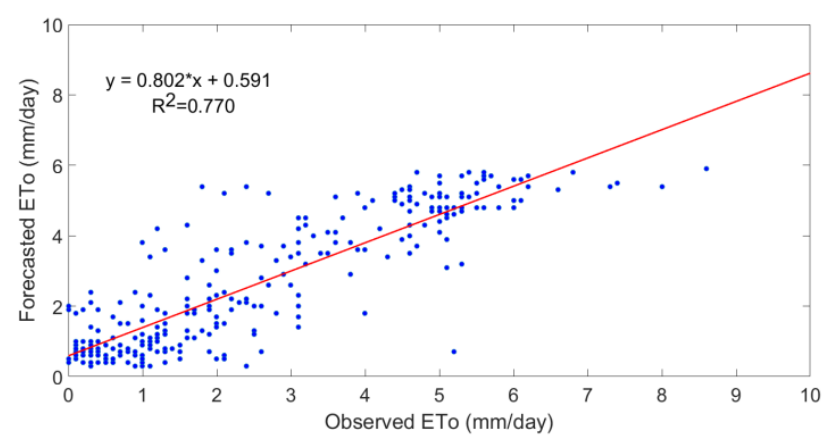

Fig.8. Scatter plot of the observed versus the forecasted $\mathrm{ET}_{\mathrm{o}}$ for two days ahead.

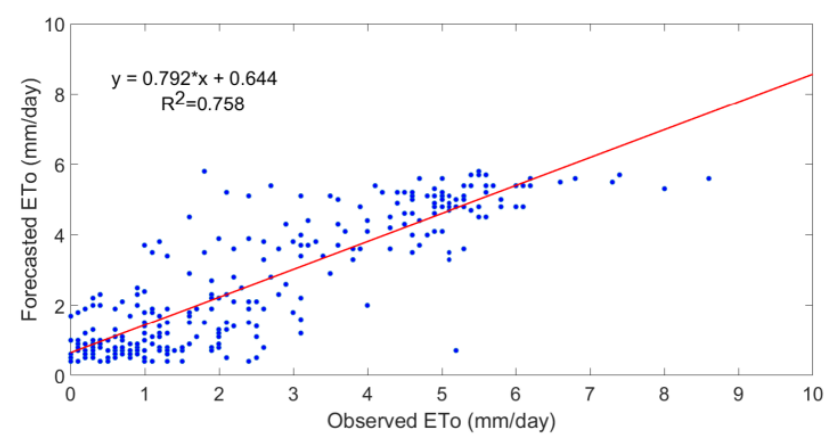

Fig.9. Scatter plot of the observed versus the forecasted $\mathrm{ET}_{\mathrm{o}}$ for three days ahead.

Accurate forecasts of $\mathrm{ET}_{\mathrm{o}}$ are necessary in efficient irrigation water management. When taking into account meteorological data such as the total daily rainfall, maximum and minimum air temperature, maximum and minimum relative air humidity, maximum wind speed, and total solar radiation on horizontal surface, it is possible to estimate $\mathrm{ET}_{\mathrm{o}}$. Additional, tests were carried out to investigate the sensitivity of model with respect to variation of parameters. Results showed that in the TLRNN, $\mathrm{ET}_{\mathrm{o}}$ was more sensitive to radiation and less sensitive to wind speed. Also, when the radiation decrease by more than $7 \%$, the $\mathrm{ET}_{\mathrm{o}}$ was more sensitive to relative humidity.

In this section, the precision to forecast $\mathrm{ET}_{\mathrm{o}}$ is examined using a TLRNN model. The procedure to forecast $\mathrm{ET}_{\mathrm{o}}$ using TLRNN model involved the calibration known as training, as well as validation stages processed versus the observed FAO-56 PM reference values. Selecting the most suitable inputs to the TLRNN is an important first step in model build up. For TLRN, a dynamic learning algorithm like backpropagation through time (BPTT) was adopted which is appropriate for temporal problems and more advanced than standard backpropagation. Meteorological data should be highly reliable and taken carefully in order to minimize possible errors. 
Forecast skill depends on which meteorological variables are utilized to forecast $\mathrm{ET}_{\mathrm{o}}$. Yang et al. [39] shown significant improvement in $\mathrm{ET}_{\mathrm{o}}$ forecast performance when wind speed is included into weather inputs rather using only the temperature. Yin et al. [40] using a hybrid bi-directional long short-term memory model, concluded that the use limited meteorological variables (maximum temperature, minimum temperature and sunshine duration) provides better performance in comparison to the corresponding other input combinations.

The results showed that the TLRNN model has a satisfying performance for one to three days ahead. The statistical analysis of the results showed that the developed TLRNN model has a remarkably satisfying ability to predict the $\mathrm{ET}_{\mathrm{o}}$ values of the following one to three days. The accuracy prediction by TLRNN model is found to be $80.7 \%, 77 \%$ and $75.85 \%$ for the first, second and third day, respectively. It is obvious that results estimating by TLRNN show that improvement are needed. Therefore, TLRNN model after minor improvement may give access to a new chance for rapid forecast of $\mathrm{ET}_{\mathrm{o}}$. The availability of accurate $\mathrm{ET}_{\mathrm{o}}$ forecasts that range up to 3 days ahead, can be helpful to individual farmers for irrigation water management and scheduling.

Table 1. Performance evaluation of the TLRNN model based on the following statistical indicators.

\begin{tabular}{llll}
\hline $\begin{array}{l}\text { TLRNN } \\
\text { Models }\end{array}$ & MBE & RMSE & IA \\
\cline { 2 - 4 } & (mm/day) & $(\mathrm{mm} /$ day $)$ & \\
\hline $1^{\text {st }}$ day ahead & +0.1 & 0.9 & 0.946 \\
$2^{\text {nd }}$ day ahead & +0.1 & 1.0 & 0.934 \\
$3^{\text {rd }}$ day ahead & +0.1 & 1.0 & 0.929 \\
\hline
\end{tabular}

\section{Conclusions}

Neural networks have become an important tool for time series forecasting, such as reference evapotranspiration $\left(\mathrm{ET}_{\mathrm{o}}\right)$ values. $\mathrm{ET}_{\mathrm{o}}$ prediction definitely plays an important role in irrigation planning. However, it must be fine-tuned for crops requirements. In this study, the reference evapotranspiration $\left(\mathrm{ET}_{\mathrm{o}}\right)$ evolution of one to three days, was successfully forecasted by the implementation of a Time Lagged Recurrent Neural Network (TLRNN) model. TLRNN is a Multilayer Perceptron Neural Network (MLPNN) with locally recurrent connections and short-term memory structures (Gamma and Laguerre) that can learn temporal variations from the dataset. Meteorological data were available from the meteorological station located in Velestino (Magnesia regional unit, central Greece). The data was based on a series of parameters such as the month number, the day number, the total daily rainfall, the maximum and minimum air temperature, the maximum and minimum relative air humidity, the maximum wind speed, the total solar radiation on horizontal surface. A good accordance between experimental and forecasted values was observed, confirming that the developed TLRNN is able to predict $\mathrm{ET}_{\mathrm{o}}$ with a tolerant error. The results of this study along with the statistical estimation, suggest that the proposed TLRNN model could be used to forecast in an acceptable extend, the $\mathrm{ET}_{\mathrm{o}}$ values of the following one to three days. Therefore, TLRNN could be successfully used to estimate $\mathrm{ET}_{\mathrm{o}}$, and demonstrates the utility of the model to provides insights into variability in crop water needs, information which can be used directly in irrigation decisions.

The next step is to repeat the project after eliminating the extreme or non-real values of the data. In addition this TLRNN model can be improved in relation to the computation speed and memory usage. From this point of view new results are expected to fit even more perfectly or at least to be very close to the results of the FAO-56 PM method. However, it must be noticed necessity of further research for safer and scientifically substantiated conclusions for $\mathrm{ET}_{\mathrm{o}}$ forecasting under different environmental conditions and input data availability. Thus, in future study, it is proposed to utilize meteorological data from more weather stations and a wide range of climatic conditions to validate the proposed methodology.

\section{References:}

[1] Papanikolaou, C., Sakellariou - Makrantonaki, M., The effect of an intelligent surface drip irrigation method on sorghum biomass, energy and water savings, Irrigation Science Journal, Vol.31, No.4, 2012, pp. 807-814.

[2] Doorenbos, J., Pruitt, W. O., Guidelines for predicting crop water requirements, FAO Irrigation and Drainage Paper, No.24, 1977, pp. 1-144.

[3] Tabari, H., Grismer, M. E., Trajkovic, S., Comparative analysis of 31 reference evapotranspiration methods under humid conditions, Irrigation Science, Vol.31, No.2, 2013, pp. 107-117.

[4] Pereira, L. S., Allen, R. G., Smith, M., Raes, D., Crop evapotranspiration estimation with 
FAO56: Past and future, Agricultural Water Management, Vol.147, 2015, pp. 4-20.

[5] Hyndman, R. J., Athanasopoulos, G., Forecasting: principles and practice, OTexts, Melbourne, 2018.

[6] Tawegoum, R., Leroy, F., Sintes, G., Chassériaux, G., Forecasting hourly evapotranspiration for triggering irrigation in nurseries, Biosystems Engineering, Vol.129, 2015, pp. 237-247.

[7] Li, Y. H., Cui, Y. L., Real-time forecasting of irrigation water requirements of paddy fields, Agricultural Water Management, Vol.31, No.3 1996, pp. 185-193.

[8] Jovic, S., Nedeljkovic, B., Golubovic, Z., Kostic, N., Evolutionary algorithm for reference evapotranspiration analysis, Comp. and electronics in agriculture, Vol.150, 2018, pp. 1-4.

[9] Gobi, I., Vimal Kumar, D., Application of Soft Computing approaches in Crop Irrigation: A survey, International Journal of Advanced Research in Computer Science and Electronics Engineering, Vol.7, No.6, 2018, pp. 16-21.

[10] Tao, H., Diop, L., Bodian, A., Djaman, K., Ndiaye, P. M., Yaseen, Z. M., Reference evapotranspiration prediction using hybridized fuzzy model with firefly algorithm: Regional case study in Burkina Faso, Agricultural Water Management, Vol.208, 2018, pp. 140-151.

[11] Di Persio, L., Honchar, O., Multitask machine learning for financial forecasting, International Journal of Circuits, Systems and Signal Processing, Vol.12, 2018, pp. 444-451.

[12] Feng, X., Kan, J., A pseudo entropy based selforganizing neural network for nonlinear system, International Journal of Circuits, Systems and Signal Processing, Vol.13, 2019, pp. 266-272.

[13] Huang, Y., Lan, Y., Thomson, S. J., Fang, A., Hoffmann, W. C., Lacey, R., Development of soft computing and applications in agricultural and biological engineering, Computers and electronics in agriculture, Vol.71, No.2, 2010, pp. 107-127.

[14] Chauhan, S., Shrivastava, R. K., Performance evaluation of reference evapotranspiration estimation using climate based methods and artificial neural networks, Water resources management, Vol.23, No.5, 2009, pp. 825-837.

[15] Traore, S., Luo, Y., Fipps, G., Deployment of artificial neural network for short-term forecasting of evapotranspiration using public weather forecast restricted messages,
Agricultural Water Management, Vol.163, 2016, pp. 363-379.

[16] Tabari, H., Talaee, P. H., Multilayer perceptron for reference evapotranspiration estimation in a semiarid region, Neural Computing and Applications, Vol.23, No.2, 2013, pp. 341-348.

[17] Traore, S., Wang, Y. M., Kerh, T., Artificial neural network for modeling reference evapotranspiration complex process in SudanoSahelian zone, Agricultural Water Management, Vol.97, No.5, 2010, pp. 707-714.

[18] Kelley, J., Pardyjak, E. R., Using neural networks to estimate site-specific Crop evapotranspiration with low-cost sensors, Agronomy, Vol.9, No.2, 2019, pp. 1-17.

[19] De Vries, B., Principe, J. C., The gamma model-A new neural model for temporal processing, Neural networks, Vol.5, No.4, 1992, pp. 565-576.

[20] Wilamowski, B. M., Irwin, J. D., Intelligent systems, CRC Press, Boca Raton, 2018.

[21] Wang, Y. M., Traore, S., Time-lagged recurrent network for forecasting episodic event suspended sediment load in typhoon prone area, International Journal of Physical Sciences, Vol.4, No.9, 2009, pp. 519-528.

[22] Kote, A. S., Jothiprakash, V., Reservoir inflow prediction using time lagged recurrent neural networks, 1st International Conference on Emerging Trends in Engineering and Technology, Nagpur, Maharashtra, 2008, pp. 618-623.

[23] Saharia, M., Bhattacharjya, R. K., Geomorphology-based time-lagged recurrent neural networks for runoff forecasting, KSCE Journal of Civil Engineering, Vol.16, No.5, 2012, pp.862-869.

[24] Allen, R. G., Assessing integrity of weather data for use in reference evapotranspiration estimation, Journal of Irrigation and Drainage Engineering, Vol.122, No.2, 1996, pp. 97-106.

[25] Principe, J. C., Kuo, J. M., de Vries, B., Backpropagation through time with fixed memory size requirements. Neural Networks for Signal Processing III - Proceedings of the 1993 IEEE-SP Workshop, Linthicum Heights, 1993, pp. 207-215.

[26] Omidvar, O., Dayhoff, J., Neural networks and pattern recognition, Academic Press, San Diego, 1998.

[27] Werbos, P. J., The roots of backpropagation: from ordered derivatives to neural networks and political forecasting, John Wiley \& Sons, New York, 1994. 
[28] Jothiprakash, V., Kote, A. S., Improving the performance of data-driven techniques through data pre-processing for modelling daily reservoir inflow, Hydrological Sciences Journal, Vol.56, No.1, 2011, pp. 168-186.

[29] Chaloulakou, A., Grivas G., Spyrellis N., Neural network and multiple regression models for $\mathrm{PM}_{10}$ prediction in Athens: A comparative assessment, Journal of the Air and Waste Management Association, Vol.53, No.10, 2003, pp. 1183-1190.

[30] Kolehmainen, M., Martikainen, H., Ruuskanen, J., Neural networks and periodic components used in air quality forecasting, Atmospheric Environment, Vol.35, 2001, pp. 815-825.

[31] Comrie, A. C., Comparing neural networks and regression models for ozone forecasting, Journal of Air and Waste Management Association, Vol.47, 1997, pp. 653-663.

[32] Willmott, C. J., Ackleson, S. G., Davis, R. E., Feddema, J. J., Klink, K. M., Legates, D. R., O'Donnell, J., Rowe, C. M., Statistics for the evaluation and comparison of models, Journal of Geophysical Research, Vol.90, 1985, pp. 8995-9005.

[33] Ferreira, L. B., da Cunha, F. F., Multi-step ahead forecasting of daily reference evapotranspiration using deep learning, Computers and Electronics in Agriculture, Vol.178, 2020, 105728.

[34] Yin, J., Deng, Z., Ines, A. V., Wu, J., Rasu, E., Forecast of short-term daily reference evapotranspiration under limited meteorological variables using a hybrid bidirectional long short-term memory model (BiLSTM), Agricultural Water Management, Vol. 242, 2020, 106386.

[35] Chauhan, S., Shrivastava, R. K., Performance evaluation of reference evapotranspiration estimation using climate based methods and artificial neural networks, Water Resources Management, Vol.23, No.5, 2009, pp. 825-837.

[36] Abrahart, R. J., See, L. M., Neural network modelling of non-linear hydrological relationships, Hydrol. Earth Syst. Sci., Vol.11, 2007, pp. 1563-1579.

[37] Le, J. A., El-Askary, H. M., Allali, M., Struppa, D. C., Application of recurrent neural networks for drought projections in California, Atmospheric Research, Vol.188, 2017, pp. 100106.

[38] Mulualem, G. M., Liou, Y. A., Application of Artificial Neural Networks in Forecasting a Standardized Precipitation Evapotranspiration Index for the Upper Blue Nile Basin,
Water, Vol.12, No.3, 2020, pp. 1-19.

[39] Yang, Y., Cui, Y., Bai, K., Luo, T., Dai, J., Wang, W., Luo, Y., Short-term forecasting of daily reference evapotranspiration using the reduced-set Penman-Monteith model and public weather forecasts. Agric. Water Manag., Vol.211, 2019, pp. 70-80.

[40] Yin, J., Deng, Z., Ines, A. V., Wu, J., Rasu, E., Forecast of short-term daily reference evapotranspiration under limited meteorological variables using a hybrid bidirectional long short-term memory model (BiLSTM), Agric. Water Manag., Vol.242, 2020, 106386.

\section{Contribution of individual authors to the creation of a scientific article (ghostwriting policy)}

Georgios Proias designed the research and coordinated all the phases for its effective implementation.

Ioannis Gravalos was responsible for results analysis and drafting of the manuscript.

Elpiniki Papageorgiou designed the methods used for the conduction of the survey.

Katarzyna Poczęta designed the methods used for the conduction of the survey.

Maria Sakellariou-Makrantonaki was responsible for data acquisition design and critical revision of the manuscript.

\section{Sources of funding for research presented in a scientific article or scientific article itself}

This research received no sources of funding.

\section{Creative Commons Attribution License 4.0 (Attribution 4.0 International, CC BY 4.0)}

This article is published under the terms of the Creative Commons Attribution License 4.0

https://creativecommons.org/licenses/by/4.0/deed.en US 